\title{
Arte da Manipulação: As Interações entre Fotografia e Arte na Era Digital
}

\author{
The Art of Manipulation: The interaction between Photography and Art in the Digital Era
}

\author{
Irene de Mendonça Peixoto \\ Universidade Federal do Rio de Janeiro, Brasil \\ peixotoirene@gmail.com
}

\begin{abstract}
The questions on this article point to a different understanding of the image with its different medias, more specifically where the digitalization and manipulation of the image unfocussed the once sharp and clear frontiers between photography and painting. The contemporary visual artists share a desire for the impurity and contagion in the relations between the photographic and the pictorial. The works alternate themselves between these bases besides exploring new relationships between them. It is not important anymore how an image derives into another, and today the term image manipulation can be applied for both photography and painting.
\end{abstract}

Keywords: Fotografia; Pintura; Manipulação digital.

\section{Introdução}

Em uma entrevista a Lawrence Weschler (1984), o pintor David Hockney aponta uma diferença na temporalidade de fruição entre a pintura e a fotografia. Ele afirma a capacidade de fazer sonhar que a pintura promove com suas pinceladas. E que ao olharmos a imagem pintada, somos capazes de intuir todo um laborioso fazer, mas quando olhamos para o instantâneo fotográfico, isto não ocorre. Para o artista, isto acontece porque o movimento do olho a percorrer a tela se reflete no movimento da mão ao pintar o quadro.

Antônio Cícero (2008), a partir desta mesma entrevista, analisa uma obra de Hockney intitulada "Pearblossom Hwy., 11th-18th April 1986" cuja imagem, ao invés de ter sido feita através de um único instantâneo fotográfico, é uma paisagem composta pela colagem de várias fotografias desta mesma paisagem. Segundo Cícero, a intenção da obra seria produzir no espectador um tempo maior de contemplação para a imagem fotográfica - "aquilo que uma fotografia não era capaz de fazer, por ser instantânea, poderia ser feito por um conjunto de fotografias articuladas, um conjunto de instantes articulados" (p.39).

As observações acima a respeito das defasagens entre o fazer pictórico e o fotográfico me interessam por acreditar que a fotografia, hoje, pode incorporar o tempo à maneira da pintura. Algumas das grandes diferenças transformadoras introduzidas pelos processos digitais na fotografia contemporânea, tanto no ato da sua realização quanto na fruição, residem nesta questão do tempo.

Como profissional da imagem com 30 anos de experiência em design gráfico, participei de uma geração que atravessou a fronteira do analógico para o digital experimentando o impacto desta travessia cotidianamente e acompanhando as infindáveis questões sobre a imagem e as novas tecnologias. Portanto, a proposta deste texto é uma análise crítica sobre as mudanças expressivas na forma de trabalhar com as imagens no ambiente digital. O que vemos surgir é uma abordagem teórico-prática diferente da habitual na conjunção da imagem com suas diversas mídias, mais exatamente onde as fronteiras entre fotografia e pintura, antes tão nítidas, começam a se desfocar.

\section{A potência do visível}

Em seus processos criativos, os artistas visuais contemporâneos compartilham, cada vez mais, o desejo de impureza e contágio nas relações da imagem entre o fotográfico e pictórico. Não se escolhe mais apenas um suporte específico. $O$ trabalho é feito alternandose entre um meio e outro, ao mesmo tempo em que se exploram as novas relações entre eles.

$\mathrm{Na}$ fotografia, por exemplo, o que antes era um trabalho considerado finalizado (o original fotográfico) passou a ser algo completamente aberto e cada vez mais passível de interferências de qualquer ordem (o arquivo eletrônico). No início, esta permissividade em relação à manipulação fotográfica gerava uma zona de conflito constante entre quem acolhia afirmativamente a questão e outros que a recusavam. Ao longo do tempo, esta postura de invasão na imagem fotográfica foi incorporada no processo de trabalho. O que antes era um constrangimento, tornou-se uma demanda de mercado. $\mathrm{Na}$ arte fotográfica, seus artistas passam a usar mais princípios pictóricos e sentem-se à vontade para manipular as aparências do mundo à maneira de um pintor.

Já em relação à pintura, podemos observar que as imagens pintadas, cada vez mais se inspiram em outras imagens extraídas de qualquer lugar, como revistas, livros ou internet. Porém, não há intenção de representar a origem material dessas referências (o 
aspecto do pixel ou a retícula do impresso) e, sim, submeter todos estes meios de representação ao desejo do artista. A pintura e a fotografia, ao desprezarem as densidades específicas das imagens que reproduzem, acabam por embaralhar as características dos diferentes meios de representação (Mammì, 2013).

No ambiente digital, o conceito de metamídia, elaborado por Manovich (2007), vai tratar desta questão exemplarmente ao destacar que todas as representações artísticas podem ser consideradas como um tipo de mapeamento. Os artistas, ao transformarem uma experiência complexa de mundo em uma imagem única, por exemplo, estariam, ao seu modo, fazendo uma leitura de dados. Em relação aos softwares, a diferença é que estes nos permitem remapear objetos de mídias antigas em formas totalmente diferentes, gerando assim uma mídia nova - a "metamídia. E, também, que a função de simulação do computador é absolutamente revolucionária porque não se trata apenas, no caso das imagens, de imitar a textura de uma pincelada de tinta ou bico de pena, mas a possibilidade de criar novas interações com os conteúdos destas mídias. A possibilidade de simular diversos meios técnicos aliada ao mapeamento de dados das imagens possibilitou uma enorme gama de misturas e recodificação de dados destas imagens.

O aparecimento de uma tecnologia capaz de gerar para uma mesma imagem uma quantidade enorme de resultados libera os artistas para experimentações diversas, fazendo com que os campos de expressão físicos e digitais se misturem e se tornem, por vezes, indiscerníveis. Esta nova prática de interferência acaba provocando um novo olhar sobre as imagens e suas representações de um modo geral, porém, mais especificamente no caso da pintura e da fotografia, vemos nascer uma categoria híbrida de artistas que não conseguem mais se intitular apenas como fotógrafos ou pintores.

A categoria de artes visuais costuma acolher bem os hibridismos artísticos do contemporâneo. Temos como exemplo a artista Loretta Lux (2006), que trabalha com imagens fotográficas extremamente manipuladas e é categórica ao afirmar que não se importa com a fotografia tradicional. O que ela quer é mais controle sobre a imagem. E por ser pintora de formação, continua gostando de pintura, apenas escolheu outro meio, o ambiente digital que é mais limpo que a tinta para trabalhar.

Para ela, o trabalho de pós-produção é tão ou mais importante do que o ato de fotografar. Muitas vezes, a imagem pronta é uma delicada colagem de vários fragmentos selecionados em diferentes tomadas de uma mesma situação ou objeto até compor a fotomontagem final. Há um controle muito maior sobre todos os elementos que compõem a imagem e o trabalho de composição, que ao organizar meticulosamente formas, texturas e cores, pode levar meses para ser concluído.

Jeff Wall (2007) é outro artista que trabalha suas imagens fotográficas dentro desta complexidade. Segundo ele, a tecnologia digital tem dois aspectos principais. O primeiro se refere às correções e aos ajustes que podem ser feitos na imagem, como contraste, saturação das cores e eliminação de sujeiras. $\mathrm{O}$ segundo são as fotomontagens que permitem que uma mesma imagem seja composta por elementos capturados em momentos distintos e combinados posteriormente. Ele pontua que fotografia é a imagem capturada em um só instante, por isso as fotomontagens seriam fotográficas, mas não seriam fotografias. O fato, agora, é que a colagem das partes no ambiente digital é imperceptível. Esta seria a grande diferença da fotomontagem contemporânea: a possibilidade delas se parecerem com fotografias de fato, uma vez que suas fronteiras, impecavelmente retocadas, são indiscerníveis. Esta indiscernibilidade entre a fotografia (o instante do mundo capturado tal como ele é) e a fotomontagem contemporânea (a simulação desejável do instante) exerce sobre nós um grande fascínio, como se a realidade do mundo pudesse ser igualmente retocada.

O que existe de interessante nas fotomontagens, analógicas ou digitais, é a representação de algo mais que o referente imediato. Alia-se uma memória, uma visão que une a vontade de criar a uma vontade de relembrar, sendo a ação da representação do tempo determinante neste sistema. E esse tipo de imagem está mais próximo de como vemos de fato, isto é, não de uma vez, mas antes em relances diversos, separados, que desenvolvemos em nossa experiência contínua do mundo.

Nas montagens fotográficas, portanto, o que se torna possível visualizar é esse trabalho do olho. O espectador tem diante de si um campo bastante vasto, povoado de imagens tomadas em diferentes distâncias, todas bem nítidas e correspondentes ao foco que o olho consegue manter nos vários ajustes que vai fazendo na experiência real.

Já nas fotomontagens digitais, o que se acrescenta é sensação de uma alucinação verdadeira do espaço, do tempo e do movimento, todos em uma mesma apresentação. A possibilidade dos ajustes finos, das passagens imperceptíveis de uma foto a outra através da equalização das cores e texturas, produzem uma narrativa visual rica em ambiguidades e absolutamente própria das técnicas digitais.

A complexidade técnica e conceitual das imagens em artistas que sabem tirar partido das novas relações entre os diferentes meios expressivos, produzem uma visualidade paradoxal, capaz de abrigar simultaneamente o realismo fotográfico e a fantasia pictórica. São imagens dotadas de uma estranheza perturbadora, justamente por não permitirem uma classificação definitiva. Percebemos a manipulação da imagem mas não sabemos classificá-la como pintura ou fotografia.

Neste ponto vale trazer o mais importante paradigma da diversidade visual contemporânea que, segundo Manovich (2008), é o "paradigma da complexidade". Para o autor, este paradigma se refere principalmente à abstração visual contemporânea, porém podemos estendê-lo a todas as imagens híbridas que combinam traços e efeitos de várias mídias. 
Na modernidade, as imagens espelhavam a concepção de um universo racional, ordenado e controlado por leis imutáveis. Já as imagens da complexidade procuram dar conta de um mundo enérgico, mutante e interconectado que reconfigura continuamente a sociedade em todos os seus aspectos. Ao percebermos os limites dos modelos lineares da ciência clássica e de seus métodos reducionistas, estamos prontos para acolher essas novas imagens, acolhedoras da complexidade do mundo, não como algo perturbador que precisa ser contido e regrado, mas como um princípio afirmativo que potencializa a nossa existência em todos os níveis.

Para Danto (2006), “o paradigma do contemporâneo é o da colagem tal como definida por Max Ernst, mas com uma diferença. Ernst disse que a colagem é o encontro de duas realidades distintas em um plano estranho a ambas. A diferença é que não existe mais um plano estranho a realidades artísticas distintas, nem essas realidades são tão distantes uma da outra". (p.7)

O paradigma da colagem em Danto encontra afinidade com o paradigma da complexidade em Manovich. Hoje, além de estarmos preparados para viver várias realidades em um só tempo, dispomos de uma tecnologia que turvou os limites das representações combinando os diferentes contextos artísticos em um grande amálgama digital. A imagem, ao abrigar em sua superfície toda a complexidade técnica e conceitual destas combinações, se torna mais densa e sua visualidade transpira esta complexidade.

Já o pensador Flusser (2002) vai abordar esta questão da fotocolagem como metáfora para uma experiência do mundo contemporâneo, propondo uma reflexão sobre o sentido da vida e a nossa possibilidade de liberdade frente ao absurdo do acaso e da morte. Neste universo fotográfico, valoramos o mundo através de nossas lembranças fotográficas. Existir em mundo mosaico, tal como apontado pelo autor, implica que "conhecer passa a ser elaborar colagens fotográficas para se ter visão de mundo" (p.66). $O$ perigo de sermos programados por estas imagens, impostas a nós como modelos de comportamento, é enorme. O pensamento fotográfico convencional, com suas imagens verdadeiras e irretocáveis, não se dá conta desta manipulação mental rumo à robotização do pensamento e crê ser livre, produtor de obras de arte que são politicamente corretas ou que contribuem para uma história da fotografia. Não se percebem como seres pós-históricos, vivem inconscientes de sua própria época.

Entretanto, segundo o autor há uma linha de fuga aberta pelos fotógrafos experimentais, aqueles que deliberadamente usam toda esta tecnologia para produzir uma imagem que não está programada, que burla os aparelhos de captura. Ao invés de serem manipulados, eles é que passam a manipular as imagens. Podemos dizer que as imagens que combinam traços e efeitos de várias mídias, fazem parte deste experimentalismo. Elas possibilitam um diálogo novo entre o fotográfico, o pictórico e o digital.
Será graças a este amálgama técnico e conceitual sobre as imagens que conseguiremos expressar toda a potência de nosso tempo. E quanto aos artistas fazedores de imagens, para conseguirem distinguir qualitativamente imagens produzidas em quantidades astronômicas, será preciso se distanciar do mero divertimento, da vulgaridade espetacular das imagens técnicas para compreender-lhes o processo de produção e capacidade de diálogo. Procurar entender quais são os fios que tecem essa rede sobre o vazio e colocá-la a serviço da ação criadora, dos diálogos autênticos e não da repetição de clichês.

Podemos dizer que passagem do analógico para o digital introduziu no pensamento visual uma complexidade bem maior na forma de abordar suas imagens. Também forneceu à fotografia capacidade maior de reinvenção para ir além da mera condição objetiva de responder por uma representação realista do mundo.

E o clique fotográfico? O fotógrafo contemporâneo considera a imagem obtida pelo clique fotográfico apenas como um dos inícios possíveis durante o processo de edição fotográfica para gerar a imagem final. Esta edição não tem começo nem fim e as imagens usadas são de qualquer natureza. Sobre este assunto, Lorenzo Mammì (2013), diz que "o processo de edição pode se iniciar de uma foto já impressa ou de uma imagem de internet, bem como um clique original, sem mudanças relevantes quanto ao seu significado essencial”. (p. 10).

Antes, a imagem obtida por uma câmera fotográfica profissional nas mãos de um fotógrafo experiente exibia uma qualidade impecável em termos de definição, contraste e saturação de cores. O trabalho posterior em laboratório de revelação e ampliação das cópias sempre existiu, mas a gama dos recursos permitidos era pequena e previsível. $\mathrm{O}$ ato de revelar uma imagem e vê-la surgir como mágica sobre a superfície do papel era um ato quase passivo na maior parte do processo. Porém, atualmente, a possibilidade de transformação é imensa. E o longo tempo investido nesta etapa, vulgarmente chamada por artistas e profissionais de "tratamento de imagem" introduz na fotografia uma temporalidade diferente do conhecido instantâneo fotográfico. O procedimento feito através de superposições de imagens, os layers, atuam como camadas que formam e transformam a imagem. Ainda temos a possibilidade de retornar em cada etapa para ir e vir sobre estas camadas, estendendo e contraindo o tempo de construção da imagem. A manipulação da imagem não tem ponto de partida ou chegada, nem diferenças de estatuto entre as suas diferentes fases.

Os fotógrafos que no início resistiam bravamente nas trincheiras do analógico, aos poucos foram seduzidos por este novo campo do conhecimento fotográfico. Perceberam não se tratava de uma revolução meramente técnica, mas, sim, conceitual. O tratamento de imagem é uma continuação do trabalho do fotógrafo, para além da técnica, fazendo com que o campo de paixão da fotografia se estenda através dele. Assim como existe um estilo de fotografar, existe agora um estilo de tratar/manipular a imagem, o 
que configura a manipulação da imagem como uma expressão dotada de subjetividade e intenção.

Outro diferencial notável é que para uma imagem ser tratada ela precisa ser "neutra". A neutralidade na imagem é um ponto crucial para se entender esta mudança de atitude do fotógrafo em relação à captação da imagem pela câmera. As imagens formadas na extensão RAW, aquelas obtidas pelas câmeras digitais profissionais, são imagens aparentemente precárias, com pouco contraste, pouco definidas e cores com pouca saturação. A imagem RAW, também chamada de "imagem em bruto", apresenta um resultado aparentemente inexpressivo e neutro. Mas, ao contrário, é esta neutralidade plena de informações que vai suportar e permitir todas as interferências que vão definir, contrastar e saturar as cores na imagem final. Ou seja, quanto mais neutra estiver uma imagem no momento de sua captação, maior o campo de possibilidades para a sua transformação. Uma câmera que apresente no momento de captação uma imagem já definida e contrastada restringiu o leque de possibilidades latentes da imagem. É o que acontece, por exemplo, com as câmeras amadoras que trabalham na extensão JPEG, um arquivo comprimido onde uma série de parâmetros já foram aplicados para que a imagem seja agradável ao olhar do leigo. As possibilidades de interferência ainda existem, mas muitas informações visuais já se perderam na compressão do arquivo.

A neutralidade da imagem é um golpe decisivo no pensamento fotográfico analógico, que sempre primou pela capacidade técnica e artística de extrair de sua câmera uma imagem bem formada. Agora, o resultado profissional que se extrai de uma máquina fotográfica, a imagem em RAW, exige obrigatoriamente uma série de procedimentos de manipulação de imagem para que o resultado final aconteça. Isto implica em dizer que, além de outra temporalidade de preparação, uma série de parâmetros visuais da imagem fotográfica serão decididos longe do referente original.

A experiência fotográfica como índice de algo que existe ou existiu, "uma emanação [literal] do referente" ( Barthes, 1984, p. 121-124) não chega a desaparecer por completo. Ela permanece na fotografia contemporânea, mas na forma de um vestígio.

A clássica relação imagem e referente foi substituída por uma condensação infinita de imagens e referências de qualquer ordem, alterando violentamente as relações estabelecidas entre um todo e suas partes. A imagem digital revela os traços da sua experiência referencial na forma de um esboço onde, através de vários procedimentos técnicos, podem sobrepor-se infindáveis camadas de outras imagens. Todas essas operações trazem um desejo de dessemelhança que provocam outras associações afetivas e significativas, que acabam se distanciando do isto-foi e indo além da captação do instante presente implicado em todo ato fotográfico e definido como a "experiência do sujeito olhado e do sujeito que olha" (Barthes, 1984, p. 21-22).
Hoje, tanto o fotógrafo quanto o pintor consideram a imagem como um lugar potencial de acontecimentos. A imagem contemporânea, mais do que em qualquer outra época, está em permanente devir. A manipulação digital vai além de retocar e modificar as imagens. Esta possibilidade se estende ao ponto de transformá-las num aberto de possibilidades que pode ser preenchido ad infinitum.

A digitalização fotográfica e a manipulação da imagem são tecnologias que revolucionaram o pensamento fotográfico e, também, o pensamento em relação a outras expressões artísticas. Nas palavras de Mammì (2013): “Não por acaso, logo que as fotos começam a se inspirar na tradição da pintura e reclamam por condições de exposição análogas, surge uma pintura que parte da fotografia ou se inspira diretamente nela. De fato, já não há distinções essenciais entre pintura e fotografia: ambas são formas de manipulação de imagem" (p.10).

O fato é que vemos questões fotográficas se misturarem com questões que antes eram apenas de ordem pictórica. Agora, não sabemos mais como uma imagem deriva na outra. Talvez porque, contemporaneamente, forma, cor, pigmento, luz, pixel, textura, tudo, seja abarcado pela imagem como a impura potência do visível. Se a modernidade nos proporcionou uma experiência de mundo através das imagens, a contemporaneidade faz o mundo acontecer dentro delas. Hoje, uma imagem sempre implicará em uma série infinita de outras imagens e a referência imediata ao objeto parece cada vez menos necessária.

\section{Referências}

Wescheler, L.(1984). True life. In Hochney, D. Cameraworks (pp. 6-41). New York, NY: Alfred A. Knopf.

Cícero, A. (2009) Sobre Pearlblossom Hwy. In Lorenzo, M, 8 X Fotografia, (pp 35-48). São Paulo: SP: Companhia das Letras.

Manovich, L. (2009). Abstração e Complexidade. In Domingues, D., Arte, Ciência e tecnologia: passado, presente e desafios (pp. 407-421). São Paulo, SP: UNESP.

Lorenzo, M. (2013). As Imagens de Passaic. In Lorenzo M.; Espada H., Catálogo da exposição Lugar Nenhum (pp. 453-484). Rio de Janeiro, RJ: Instituto Moreira Salles, 453-484.

Benedictus, L. (2006, November 11). Loretta Lux Best Shots. The Guardian.

Rondeau, J. (2007). Entrevista com Jeff Wall. In Catálogo da Exposição Jeff Wall (pp. XXXX). New York, NY: The Museum of Modern Art and San Francisco Museum of Modern Art

Manovich, L (2007). O excesso de dados e o belo artigo. Cibercultura. http://www.cibercultura.org.br/tikiwiki/tikiread_article.php?articleld $=18$

Danto, A. (2006). Após o Fim da Arte: A Arte Contemporânea e os Limites da História. São Paulo, SP: Odysseus Editora.

Flusser, V. (2002). Filosofia da Caixa Preta. Rio de Janeiro, RJ: Relume Dumará.

Barthes, R. (1984) A câmara clara. Nota sobre a fotografia. Rio de Janeiro, RJ: Nova Fronteira. 